\title{
CFD MODELING OF AERODYNAMIC CAR BRAKE COOLING SYSTEM
}

\author{
Florin-Bogdan MARIN, Mihaela MARIN \\ "Dunarea de Jos" University of Galati, Romania \\ e-mail: flmarin@ugal.ro
}

\begin{abstract}
The objective of this experimental research is to identify solutions for an optimal cooling of the disks. The aerothermal brake cooling calculation is used to determine how the brake cooling process evolves. The techniques for simulating the dynamics of the CFD fluid allow us to simulate the cooling of the brakes in air current and then to compare the results obtained in the wind tunnel.
\end{abstract}

KEYWORDS: CFD, modeling, simulation, car brake, cooling

\section{Introduction}

The braking system is an important control system of an automotive. Computational Fluid Dynamics (CFD) is the part of CAE that analysis the fluid motion and heat transfer using numerical solution methods. This technology is used in many industries like aeronautical engineering, electronics engineering, HVAC engineering, automotive, medical research, power generation, chemical engineering and way more [1-13].

CFD can be used to simulate disc brake cooling system. There are some differences between aerothermal calculation and classical CFD calculation. These differences are located on the elements that will be coupled. As for the rest of the vehicle, the geometry preparation is similar to a simulation of external air flow. Aerothermal calculations on the brake proved to be complex and time-consuming for implementation, due to the large number of steps prior to the calculation of the cooling constant. The aerothermal brake cooling calculation is used to determine how the brake cooling process evolves. The techniques for simulating the dynamics of the CFD fluid allow to simulate the brakes cooling in air current and then to compare the results contained in the wind tunnel. In addition, given the expectation of this type of calculation, to prepare the parts of the front wheel assembly, which will be used later in the thermal coupling, a special care is required. The different meshing stage depending on the surfaces of the brake system components is a particular interest [14-20]. In the brake system, a major problem is the overheating between disc brake and brake pad. To avoid this process, the heat generated should be evacuated into the atmosphere.

Brake cooling aerothermal calculation is used in order to determine a constant related to brake cooling. Brake cooling simulation requires coupled simulations as well as coupled calculations. Front wheel air deflector poses an important place in better cooling the brakes as it orientates the flow of air in order to assure a better cooling. In this paper we aim to determine dimension of the front wheel air deflector for specific scenario.

\section{Experimental procedure}

In the first stage we prepare the models for aero, thermal and coupled calculations. These calculations require several preparation steps before a simulation is launched. For aerodynamic calculation, to clean the geometry of intersections of surfaces, lines and points is a necessary step. After the geometry is cleaned, the geometry is meshed, the conditions are set and the calculation is launched. In the case of thermal calculation, the geometry of the brake assembly is cleaned, the contacts between the PIDs are created, the conditions are set and then the calculations are launched. Finally, the two calculations are coupled and then released to determine the cooling of the brake. The brake cooling is calculated thermally, transiently and consequently an independent calculation is made.

The results of the brake cooling calculation are processed compared with the results obtained in the wind tunnel, where the physical product is tested at different wind speeds. 
The physical tests are performed by heating the disc, by repeated braking and acceleration in as short a time as possible to a temperature of $600{ }^{\circ} \mathrm{C}$, maintaining this temperature for 4 minutes and then allowing it to cool in the air for 10 minutes until reaches ambient temperature $\left(20{ }^{\circ} \mathrm{C}\right)$. We have simulated the cooling of car breaks in several situations. The brake cooling is calculated thermally, transiently and an independent calculation is made. The purpose of the simulations is to determine how the brakes are cooled for the general purpose of identifying methods to improve their cooling. The scenarios considered take into account extreme conditions of ambient temperature as well as disk temperature. The simulation setup takes into account, also, the rotation of the wheels. The surface on which the car (road) rests does not move - a matter that is not respected for the total replication of situations in reality. However, the influence of road traffic does not influence the cooling of the brakes as there is an important distance between the disc and the road. In this research, the following conditions are considered: car speed: $100 \mathrm{~km} / \mathrm{h}$, disc temperature of the brake: $400{ }^{\circ} \mathrm{C}$, outdoor temperature: $20{ }^{\circ} \mathrm{C}$ and wind speed of $0 \mathrm{~km} / \mathrm{h}$.

\section{Results and discussions}

Fig. 1. Shows the 3D model considered at a real scale. In Figure 2 is presented the three variations of the dimension (depth) of air deflector.

Fig. 3 shows the temperature variation in a vertical plane at a distance of $5 \mathrm{~mm}$ from the brake disc. The fluid temperature distribution is also observed. The higher temperature is towards the back of the car and it is observed that in the space between the wheels, under the body, there is a temperature around $44{ }^{\circ} \mathrm{C}$. If the car had an acute lower ground clearance, the temperature would have been higher. If there were plastic components (pipe guards, decorative elements) the relatively high temperature would influence both its strength and aging.

In Fig. 4 we observe the temperature distribution in a plane at $300 \mathrm{~mm}$ from the wheel plane in which the results show that the components of the front wheel braking elements will be better cooled than the rear ones. It follows that the geometry of the car must be intervened in order to improve the cooling of the rear wheel.

In Figures. 4 and 5 are observed that the fluid trajectories are different, as we previously concluded. This results in a different cooling.

In Fig. 6 is observed that the design of the rim allows a good cooling, acting as a fan, which allows the rapid air evacuation to cool the braking components.
In Fig. 7, which shows the temperature distribution in the front wheel area, it is observed that the air currents that are deviated from the side of the rim and the tire from the front, do not allow uniform cooling of the disc. It is observed that if the disk were arranged further inwards, the situation would change and the cooling would be better. However, there are other conditions related to the braking mechanism, wheel resistance, protection of the disc from rain and objects that can hit the disc (such as stones).

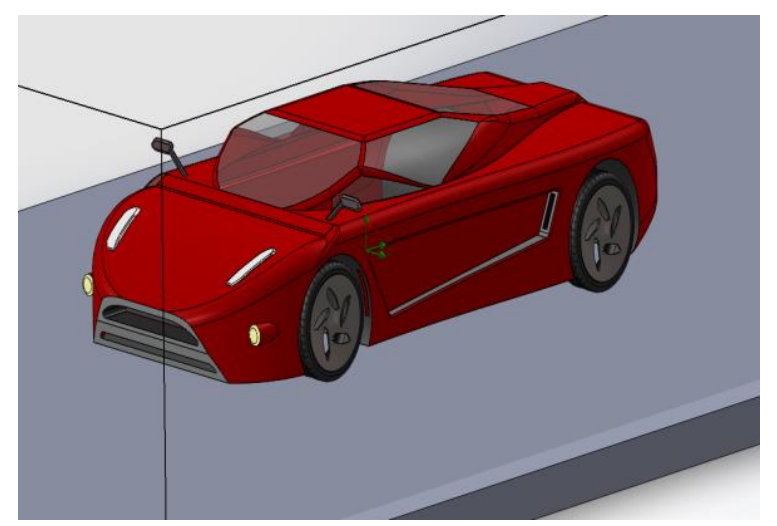

Fig. 1. 3D CAD model considered

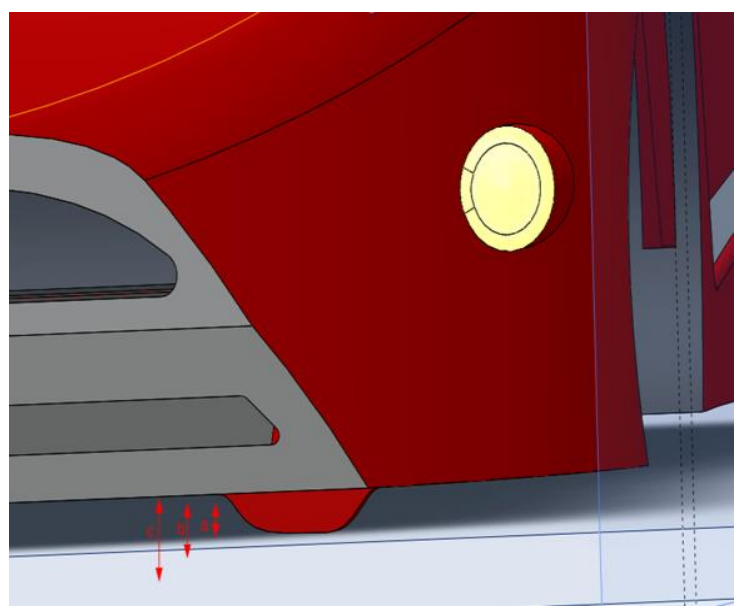

Fig. 2. The three scenarios considered as dimensions for the front wheel deflector case a$60 \mathrm{~mm}$ case b $80 \mathrm{~mm}$ and $\mathrm{c} 120 \mathrm{~mm}$

We considered three cases where the depth of the air deflector is $60 \mathrm{~mm}, 80$ and $120 \mathrm{~mm}$ respectively (as seen in Figure 2). The results showed that the second case $b$, with the dimension of $80 \mathrm{~mm}$ mean better cooling of the brake disc with an average of $10^{\circ} \mathrm{C}$ degree for the scenario considered. The third case where de depth of deflector is $120 \mathrm{~mm}$ indicated worse cooling than a case and $b$ case. It seems that the air is deflector to a region of the brake disc and the air is not director to the rim to the exterior of the car as it should. 


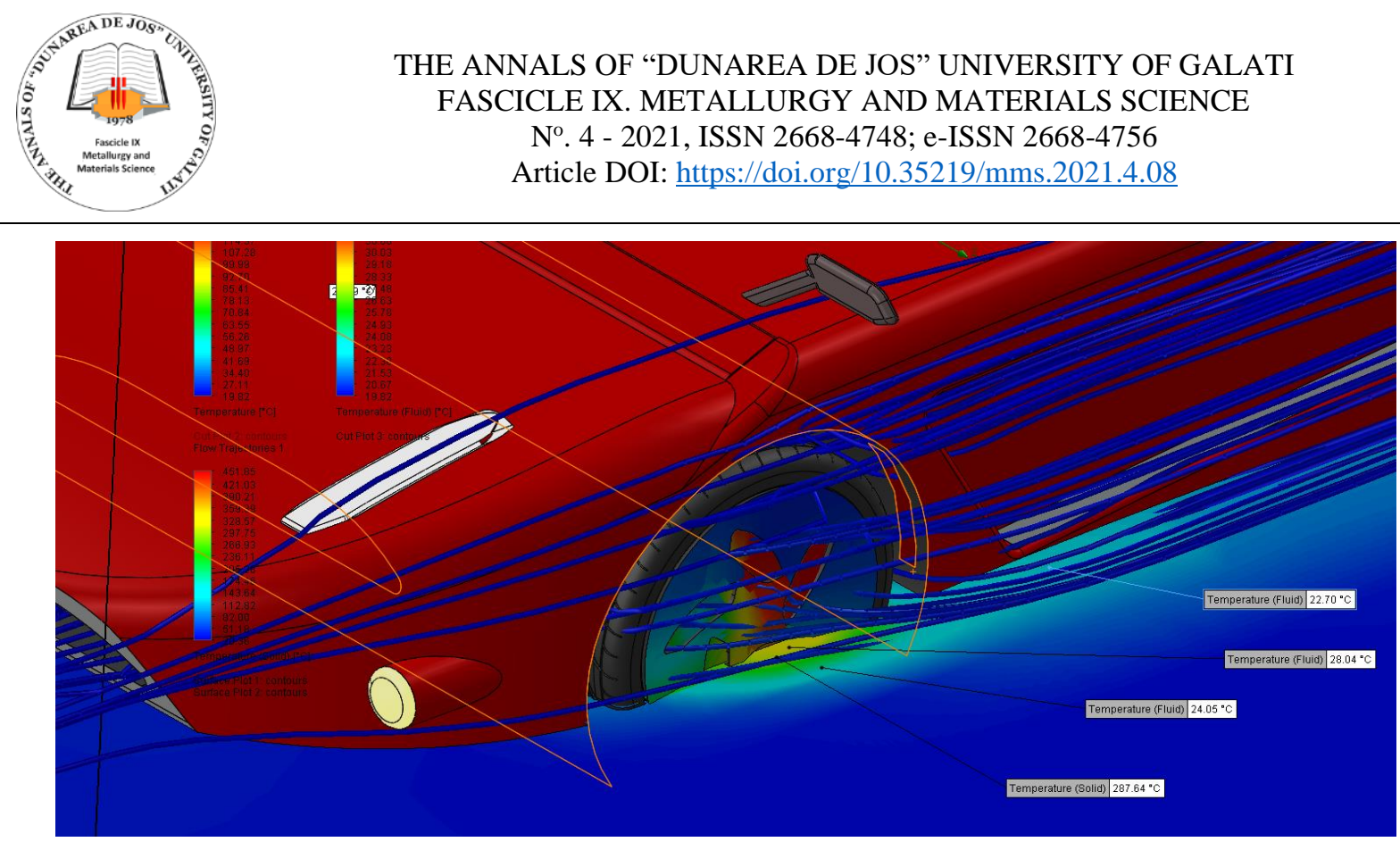

Fig. 3. Fluid trajectories and temperature distribution

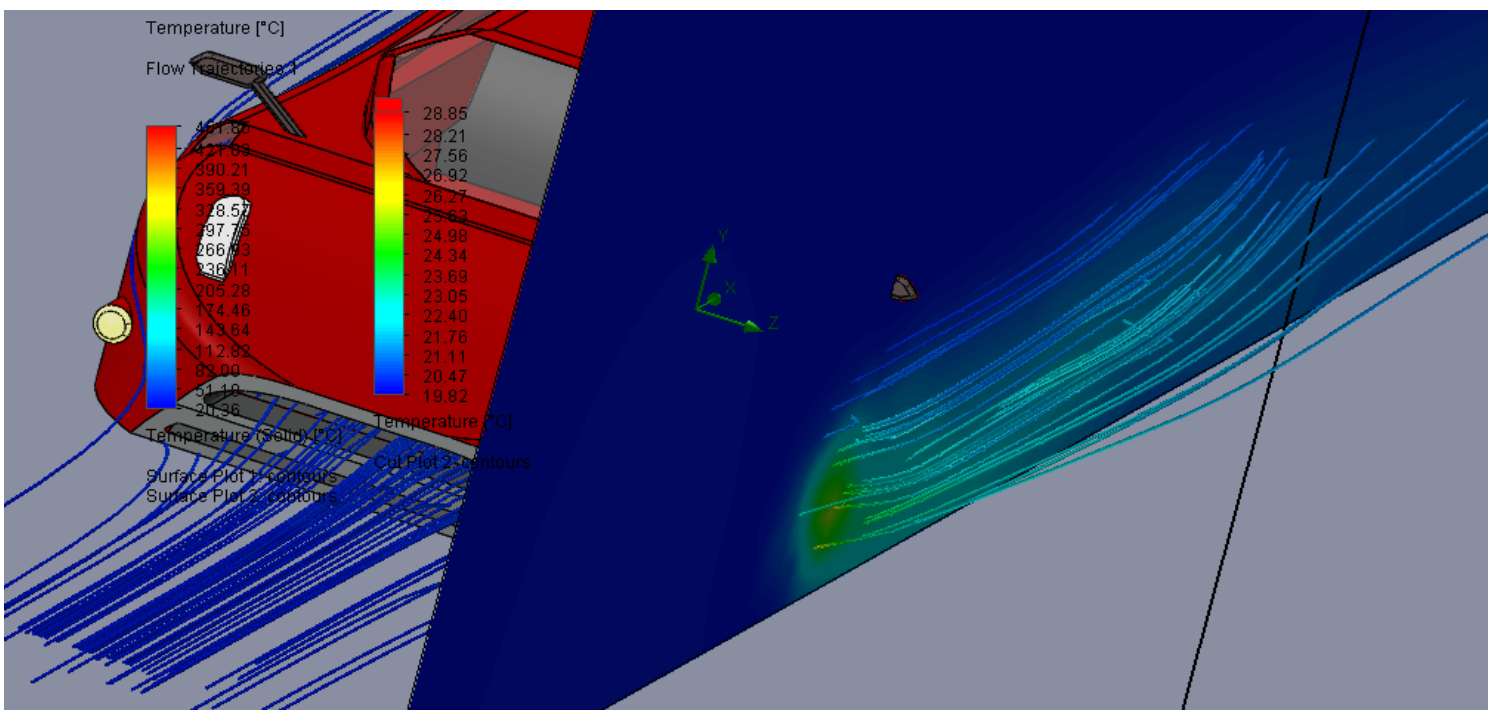

Fig. 4. Temperature distribution in a horizontal plane at a distance of $200 \mathrm{~mm}$ from the ground

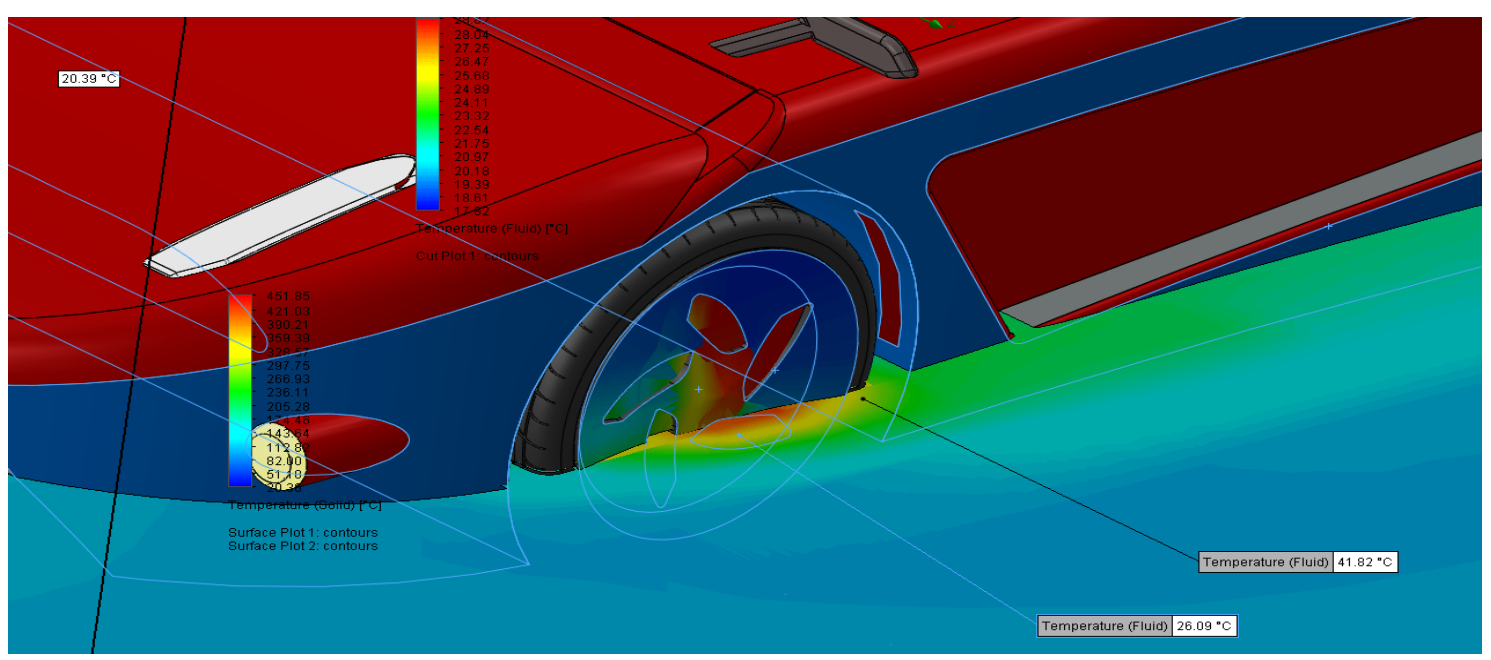

Fig. 5. Temperature distribution in the front wheel area 


\section{Conclusions}

The main conclusions are the following:

- Braking system cooling is an important objective both for the safe operation of the braking system and especially for not affecting other components.

- The brake disc heating determines the heat transfer to other components and is a particularly important part for the design of the braking system.

- From simulated scenario, it was observed that the rim design allowed a good cooling, acting as a fan, which allowed the rapid air evacuation to cool the braking components.

- The design of front wheel deflector is important taking into account the car body and rim dimensions.

- Further development should refer to compare different design of the deflector for different car speeds.

\section{References}

[1]. Silvestri L., CFD modeling in Industry 4.0: New perspectives for smart factories, Procedia Computer Science, vol. 180, p. 381387, ISSN 1877-0509, 2021.

[2]. Wutz J., Waterkotte B., Heitmann K., Wucherpfennig T. Computational fluid dynamics (CFD) as a tool for industrial UF/DF tank optimization, Biochemical Engineering Journal, vol. 160, 107617, ISSN 1369-703X, 2020.

[3]. Moon H.-G., Park S., Ha K., Jeong J.-H., CFD-Based InDepth Investigation of the Effects of the Shape and Layout of a Vortex Generator on the Aerodynamic Performance of a Multi-MW Wind Turbine, Appl. Sci. 2021, 11, 10764. https://doi.org/10.3390/app112210764, 2021.

[4]. Pavlin-Premrl D., Sethu R., Nemes A., Mohammadzadeh M., Monajemi S., Brian S., Campbell C. V., Computational Fluid Dynamics in Intracranial Atherosclerosis - Lessons from Cardiology: A Review of CFD in Intracranial Atherosclerosis, Journal of Stroke and Cerebrovascular Diseases, vol. 30, issue 10, 106009, ISSN 1052-3057, 2021.
[5]. Zobaer T., Sutradhar A., Modeling the effect of tumor compression on airflow dynamics in trachea using contact simulation and CFD analysis, Computers in Biology and Medicine, vol. 135, 104574, ISSN 0010-4825, 2021.

[6]. Perinajov R., Juffermans J., Westenberg J. M., Roel L. F., Palen Pieter J., Boogaard Hildo J., Lamb Sas a Kenjeres, Geometrically induced wall shear stress variability in CFD-MRI coupled simulations of blood flow in the thoracic aortas, Computers in Biology and Medicine, vol. 133, 104385, ISSN 00104825, 2021.

[7]. Shoeibi S., Kargarsharifabad H., Rahbar N., Ahmadi G., Reza M. S., Performance evaluation of a solar still using hybrid nanofluid glass cooling-CFD simulation and environmental analysis, Sustainable Energy Technologies and Assessments, vol. 49, 101728, ISSN 2213-1388, 2022.

[8]. Zhu X., Dai Y., Ma F., CFD modelling and numerical simulation on windage power loss of aeronautic high-speed spiral bevel gears, Simulation Modelling Practice and Theory, vol. 103, 102080, ISSN 1569-190X, 2020.

[9]. Fujii K., Progress and future prospects of CFD in aerospaceWind tunnel and beyond, Progress in Aerospace Sciences, vol. 41, issue 6, p. 455-470, ISSN 0376-0421, 2005.

[10]. Xia H., Tucker P. G., Dawes W. N., Level sets for CFD in aerospace engineering, Progress in Aerospace Sciences, vol. 46, issue 7, p. 274-283, ISSN 0376-0421, 2010.

[11]. Wang C., Li F., Ding Z., Zhang L., Numerical Simulation of Hypersonic Flow Around an Aerospace Plane by Parallel RANS based CFD, Procedia Engineering, vol. 61, p. 23-27, ISSN 18777058,2013

[12]. Rizzi A., Jluckring J. M., Historical development and use of CFD for separated flow simulations relevant to military aircraft, Aerospace Science and Technology, vol. 117, 106940, ISSN 12709638, 2021.

[13]. Wang M., Wang Y., Tian W., Qiu S., Su G. H., Recent progress of CFD applications in PWR thermal hydraulics study and future directions, Annals of Nuclear Energy, vol. 150, 107836, ISSN 0306-4549, 2021.

[14]. Seshaiah T., Vasu B., Vijaya K., Reddy K., Bridjesh P., Analysis on air craft winglet at different angles by using CFD simulation, Materials Today: Proceedings, ISSN 2214-7853, 2021.

[15]. Garcia-Ribeiro D., Flores-Mezarina J. A., BravoMosquera P. D., Cerón-Muñoz H. D., Parametric CFD analysis of the taper ratio effects of a winglet on the performance of a Horizontal Axis Wind Turbine, Sustainable Energy Technologies and Assessments, vol. 47, 101489, ISSN 2213-1388, 2021.

[16]. Zurin W. M., Talib R. J., Ismail N. I., Thermal Analysis on Motorcycle Disc Brake Geometry, International Conference on Applied Physics and Engineering (ICAPE2016) AIP Conf. Proc. 1875, 030022-1-030022-8, doi: 10.1063/1.4998393, 2017. 